\title{
Reduction in Common Rust Severity Conferred by the Rp1D Gene in Sweet Corn Hybrids Infected by Mixtures of Rp1D-Virulent and Avirulent Puccinia sorghi
}

\author{
Jerald K. Pataky and M. Andrea Campaña, Department of Crop Sciences, University of Illinois, Urbana 61801
}

\begin{abstract}
Pataky, J. K., and Campaña, M. A. 2007. Reduction in common rust severity conferred by the Rp1D gene in sweet corn hybrids infected by mixtures of Rp1D-virulent and avirulent Puccinia sorghi. Plant Dis. 91:1484-1488.

The Rp1D gene confers a hypersensitive, chlorotic-fleck, resistant reaction to Puccinia sorghi, the casual agent of common rust of corn. About $40 \%$ of commercial sweet corn hybrids carry the $R p 1 D$ gene. Sine 1999, Rp1D-virulent (D-virulent) isolates of P. sorghi have occurred regularly in populations of $P$. sorghi in North America. Observations from sweet corn hybrid nurseries and other trials indicate that the frequency of D-virulent isolates affects severity of rust on Rp1D hybrids; however, the frequency of D-virulence at which the Rp1D gene is rendered completely ineffective is not known. The objective of this study was to assess whether common rust severity is reduced by the $R p 1 D$ gene in sweet corn hybrids infected by mixtures of D-virulent and Rp1D-avirulent (avirulent) P. sorghi. Forty pairs of Rp1D-resistant and susceptible (rp1d) versions of sweet corn hybrids from six different commercial breeding programs were evaluated in 2003 and 2004 in trials inoculated with one of five different ratios of avirulent:D-virulent inocula: 100:0, 90:10, 80:20, 60:40, or 0:100. When D-virulent $P$. sorghi was 100\% of initial inoculum, common rust was equally severe on Rp1D and rp1d versions of the same hybrid. Thus, the Rp1D gene did not confer partial or residual resistance in these trials. When initial inocula consisted of $40 \%$ or less D-virulent $P$. sorghi, rust was significantly less severe on Rp1D versions than on rp1d versions of the same hybrids. Relationships between rust severity on Rp1D and rpld versions of hybrids were explained by linear regressions in all trials. Slope coefficients (i.e., rust severity on Rp1D hybrids as a proportion of that on rp1d hybrids) were related to the percentage of D-virulent $P$. sorghi in the initial inoculum and were $0.21,0.29,0.51,0.64$, and 0.93 in 2003 and $0.25,0.50,0.67,0.76$, and 1.0 in 2004 for trials inoculated with $0,10,20,40$, and $100 \%$ D-virulent $P$. sorghi, respectively. Thus, the Rp1D gene may convey levels of control in proportion to the frequency of virulence in mixed populations of D-virulent and avirulent $P$. sorghi when the frequency of virulent isolates is less than $40 \%$.
\end{abstract}

Additional keywords: rust resistance

Common rust, caused by Puccinia sorghi Schwein., reduces sweet corn yield about 0.2 to $0.7 \%$ for each $1 \%$ leaf area infected at harvest $(4,6,13,18,24)$. Rust often is the most prevalent disease of lateseason processing sweet corn grown in the midwestern United States (5). Host resistance is the most efficient way to control common rust (9). Specific resistance to $P$. sorghi (i.e., $R p$-gene resistance) is characterized by a hypersensitive reaction that results in chlorotic flecks with little or no formation of uredinia. Over $25 R p$ genes have been identified in maize and Tripsacum sp. $(2,8,9)$. The $\mathrm{rp} 1$ region of the short arm of maize chromosome 10 is a complex structure of rust resistance genes that includes a single dominant resistance gene, Rp1D (10). From 1985 to 1999, re-

Corresponding author: J. K. Pataky

E-mail: j-pataky@uiuc.edu

Accepted for publication 25 June 2007.

doi:10.1094/PDIS-91-11-1484

(C) 2007 The American Phytopathological Society sistance conferred by the RplD gene effectively controlled rust in processing sweet corn grown in the Midwest. Based on relatively conservative estimates, $\mathrm{Rp}$ resistance added nearly $\$ 3$ million annually during this period to the on-farm value of processing sweet corn.

Sweet corn breeders preferred the $R p 1 D$ gene rather than general resistance or other $R p$ genes because the $R p 1 D$ gene could be backcrossed easily into susceptible inbred lines and it was effective against all known populations of $P$. sorghi in North America $(5,8,10,14)$ except for an isolate collected in Illinois in 1982 (3), an observation in Georgia in 1989 (5), and an isolate collected in Kansas in 1990 (11). Nearly 40\% of over 650 sweet corn hybrids available commercially in 2004 carried the $R p 1 D$ gene (15). In August and September 1999, isolates of $P$. sorghi were collected from Rp1D-resistant sweet corn grown in Illinois, Wisconsin, Minnesota, Michigan, and New York. This was the first widespread occurrence in North America of P. sorghi virulent on corn with the RplD gene (22).

Since 1999, Rp1D-virulent (D-virulent) isolates have occurred in populations of $P$. sorghi throughout North America $(21,23)$ but the frequency of D-virulent isolates within these populations has not been documented. The frequency of D-virulent isolates should affect severity of rust on hybrids with the $R p 1 D$ gene. Observations from sweet corn hybrid disease nurseries and other trials support this hypothesis $(16,19,20)$. For example, rust was nearly twice as severe on 156 hybrids without the $R p 1 D$ gene (rp1d hybrids) as on $86 \mathrm{Rp} 1 \mathrm{D}$ hybrids when plants in the University of Illinois sweet hybrid disease nursery were inoculated with avirulent $P$. sorghi in 2000 and D-virulent isolates occurred naturally, presumably at a low frequency (Fig. 1A; $16,20)$. Conversely, in 2001, when hybrids in the disease nursery were inoculated with D-virulent $P$. sorghi, severity did not differ between groups of 137 Rp1D hybrids and 176 rp1d hybrids (Fig. 1B; 16,19). The 2000 nursery included seven pairs of rp1d and Rp1D versions of sweet corn hybrids (i.e., a susceptible hybrid and the same hybrid with at least one inbred parent converted to Rp1D resistance via backcrossing). In 2001, a D-virulent inoculated trial contiguous with the hybrid disease nursery included 40 pairs of rp1d and Rp1D versions of hybrids (16). When rust severity on the Rp1D versions of hybrids was plotted against severity on the rpld versions of the same hybrids, slope coefficients were 0.49 and 0.96 in 2000 and 2001, respectively (Fig. 2). Based on these observations, we hypothesized that rust severity was reduced by the $R p 1 D$ gene when D-virulent isolates occurred at a low frequency in 2000, but severity was not affected when D-virulent isolates were frequent in 2001. However, we did not have an experimentally derived basis from which to estimate the frequency of Dvirulent isolates in the 2000 trial; nor did we know the frequency of D-virulence at which the RplD gene is rendered completely ineffective. Thus, the objective of this study was to assess whether severity of rust is reduced by the $R p 1 D$ gene in sweet corn hybrids infected by mixtures of $D$ virulent and Rp1D-avirulent (avirulent) $P$. sorghi.

\section{MATERIALS AND METHODS}

Forty pairs of Rp1D-resistant and susceptible (rp1d) versions of sweet corn hybrids from six different commercial breeding programs were evaluated in trials at the University of Illinois South Farms, Urbana, in 2003 and 2004. The degree to 
which the paired hybrids were nearly isogenic varied. Inbreds into which the RpID gene was incorporated were at least $87.5 \%$ homogeneous with the rp1d version of the inbred as a result of backcrossing to the recurrent parent for three or more generations. Thus, Rp1d and rp1d versions of hybrids were at least $93.75 \%$ homogeneous.

In each year, there were five separate trials inoculated with various proportions of D-virulent and avirulent P. sorghi. All five trials were planted in fields that were at least $1.2 \mathrm{~km}$ apart in order to prevent the spread of inocula among trials. Trials were planted 20 May 2003 and 21 May 2004. In each trial, treatments were arranged in a 2by-40 factorial of a randomized split block design with four replicates. Main plots consisted of sweet corn hybrids. Subplots were planted with the Rp1D or rp1d version of a hybrid. Each experimental unit consisted of a one-row plot with about 15 plants per 4-m row. Rows were spaced 76 cm apart.

Plants between the one- and four-leaf stages were inoculated three times within a week by spraying urediniospore suspensions directly into leaf whorls. All trials were inoculated the same days: 20,24, and 26 June 2003 and 15, 18, and 22 June 2004. Each trial was inoculated with one of five different ratios of avirulent:Dvirulent inocula: 100:0, 90:10, 80:20, 60:40, or $0: 100$. Isolates of avirulent and D-virulent $P$. sorghi were collected in previous years and maintained at $-80^{\circ} \mathrm{C}$. Virulence of isolates was confirmed in the greenhouse by inoculating a differential set of plants carrying the $R p 1 D, R p G, R p 1 I$, or no known $R p$ genes. Urediniospores were increased in isolated 0.2-ha fields planted in mid-April at the University of Illinois South Farms. D-virulent inoculum was produced on two hybrids with the RplD gene, WHT2801 and Bold. These hybrids have highly susceptible reactions to the Dvirulent race (17). Avirulent inoculum was produced on two susceptible hybrids, Sweet Magic and Snow White. Prior to the first inoculation of trials each year, leaves covered with profusely sporulating uredinia were collected from the 0.2-ha inoculum-increase plots and cut into 5-by-10-cm pieces with similar densities of uredinia (i.e., bands of heavily infected leaf tissue). Leaf pieces were stored in a refrigerator for a maximum of 8 days until used to produce urediniospore suspensions. Each batch of inoculum was prepared from $1,20050-\mathrm{cm}^{2}$ infected leaf pieces in the following ratios of avirulent:D-virulent $P$. sorghi: 1200:0, 1080:120, 960:240, 720:480, and 0:1200. Immediately before inoculating plants, leaf pieces were washed vigorously for 3 minutes in 4 liters of water and $10 \mathrm{ml}$ of Tween 20 to produce urediniospore suspensions. Concentrated suspensions were diluted to 23 liters. Handheld garden sprayers were used to place approximately $5 \mathrm{ml}$ of diluted inoculum into each plant whorl. Each year, inoculum concentration was estimated from five replicate samples of $1050-\mathrm{cm}^{2}$ infected leaf pieces of both $P$. sorghi isolates. Leaf pieces were washed in $200 \mathrm{ml}$ of water and a drop of Tween 20 and then diluted to 2 liters. Hemacytometers were used to count urediniospores from eight subsamples from each of the five replicate samples. Concentrations of urediniospores in diluted inocula were estimated to be 6.9 $\pm 1.2 \times 10^{3} \mathrm{ml}^{-1}$ and $7.8 \pm 1.6 \times 10^{3} \mathrm{ml}^{-1}$ for D-virulent and avirulent $P$. sorghi, respectively, in 2003 and $2.4 \pm 0.6 \times 10^{4} \mathrm{ml}^{-1}$ and $2.2 \pm 0.7 \times 10^{4} \mathrm{ml}^{-1}$ for D-virulent and avirulent $P$. sorghi, respectively, in 2004.

Rust severity was assessed visually on a row basis as the percentage (on a linear scale from 0 to $100 \%$ ) of the total leaf area infected when plants were at sweet corn harvest stage ( 3 weeks past anthesis). Two people individually rated each row, and the two ratings were averaged. Plants were rated between 4 and 6 August 2003 and between 27 and 30 July 2004. Data were analyzed by analysis of variance. Hybrids were compared by mean separation values (BLSD $k=100$ ). Correlation coefficients were calculated among trials based on mean severity of rust on each of 80 hybrids. Rust severity also was correlated among trials for the two groups of 40 Rp1D and rp1d hybrids. Severity of rust on Rp1D and rp1d hybrids also was compared by regression analysis where severity on the Rp1D version of a hybrid was the dependent variable and severity on the rpld version of a hybrid was the independent variable. Slope coefficients $\left(b_{1}\right)$ which estimated rust severity on Rp1D hybrids as a proportion of that on rpld hybrids were compared among trials with $0,10,20,40$, and $100 \%$ Dvirulent initial inocula. Reduction in rust severity as a result of the $R p 1 D$ gene was estimated as $\left(1-b_{1}\right) \times 100$.

\section{RESULTS}

Only two infection types were observed in these trials: fully susceptible uredinia

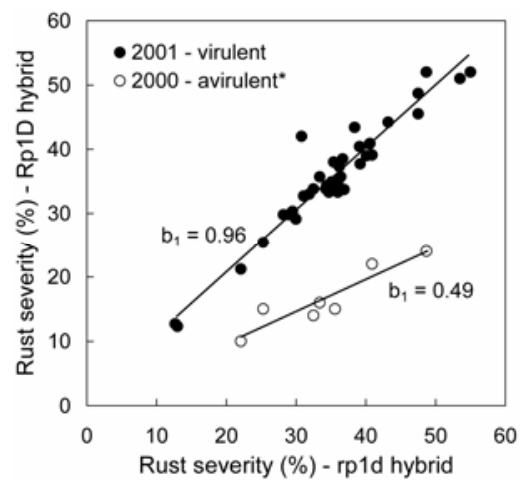

Fig. 2. Rust severity on of pairs of Rp1D and rp1d versions of sweet corn hybrids inoculated with Rp1D-avirulent isolates of Puccinia sorghi (* and infected by naturally occurring Rp1D-virulent $P$. sorghi) in 2000 and inoculated with Rp1Dvirulent isolates of $P$. sorghi in 2001. Slope coefficients $\left(b_{1}\right)$ estimate the severity of rust on the Rp1D version of a hybrid as a proportion of the severity on the rpld version of a hybrid.
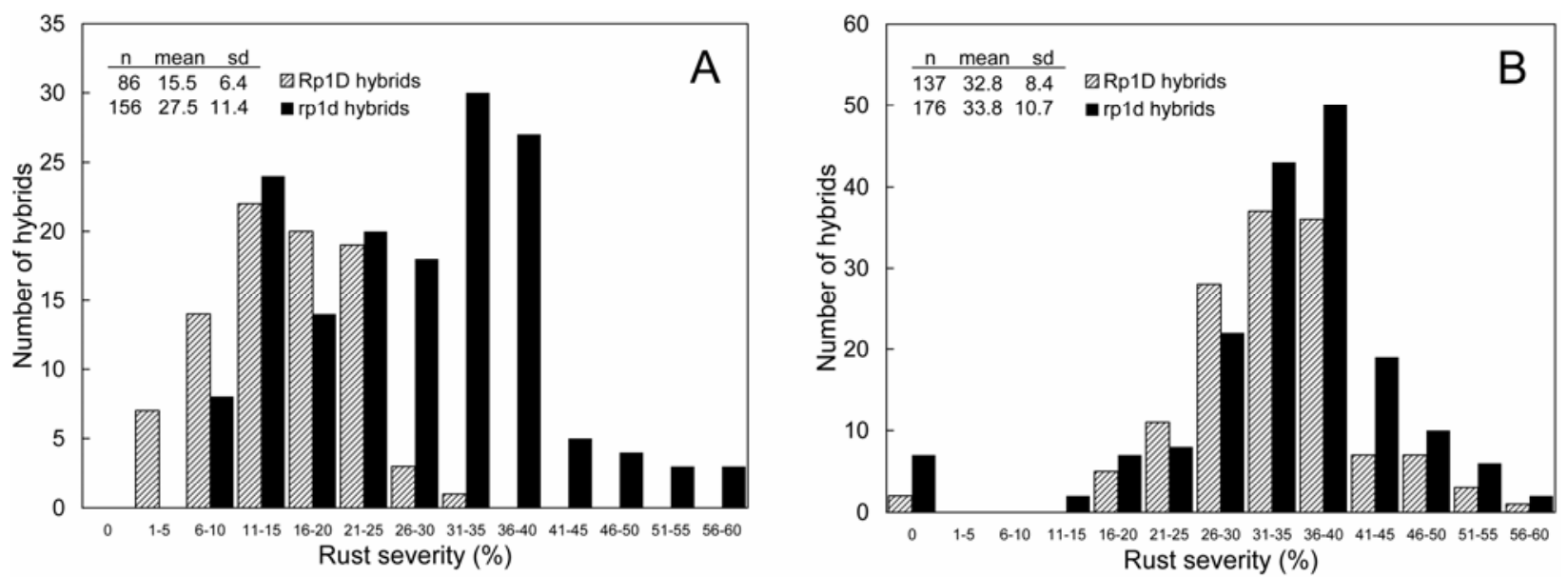

Fig. 1. Distributions of reactions of hybrids with or without an $R p 1 D$ gene in University of Illinois sweet corn hybrid disease nurseries following A, inoculation with Rp1D-avirulent isolates of Puccinia sorghi and infection from naturally occurring Rp1D-virulent $P$. sorghi in 2000 and $\mathbf{B}$, inoculation with Rp1Dvirulent isolates of $P$. sorghi in 2001 . 
(i.e., type-4 infections) and chlorotic flecks (i.e., type-0; infections) typical of Rpresistant reactions. Severity of rust ranged from 0.4 to $72 \%$ and from 3 to $78 \%$ among hybrids in 2003 and 2004, respectively (Table 1). In both years, the effects of hybrids and $R p$ genes and the hybrid- $R p$ gene interaction term were significant $(P<$ 0.01 ) in the analyses of variance of rust severity in trials inoculated with $0,10,20$, or $40 \% \mathrm{D}$-virulent $P$. sorghi; however, the effects of $R p$ genes and the hybrid- $R p$ gene interaction terms were not significant in either trial inoculated with $100 \%$ Dvirulent $P$. sorghi. Similarly, the mean severity of rust on Rp1D hybrids was less than that on rp1d hybrids in each trial inoculated with $0,10,20$, or $40 \%$ Dvirulent $P$. sorghi; whereas, mean rust severity did not differ significantly among the group of Rp1D and rpld hybrids in either trial inoculated with $100 \%$ Dvirulent $P$. sorghi (Table 1). Mean rust severity on Rp1D hybrids as a proportion of mean rust severity on rp1d hybrids in trials inoculated with $0,10,20,40$, and $100 \%$ D-virulent inoculum was 0.23 , $0.34,0.47,0.67$, and 0.97 , respectively, in 2003, and $0.33,0.56,0.69,0.78$, and 1.0, respectively, in 2004.

Severity of rust on the 80 hybrids was highly correlated among the four trials inoculated with $0,10,20$, or $40 \%$ Dvirulent $P$. sorghi (Table 2). Correlation coefficients ranged from 0.85 to 0.96 in 2003 and from 0.71 to 0.94 in 2004 . Correlation of rust severity on the 80 hybrids was low among the trials inoculated with $100 \%$ D-virulent $P$. sorghi and trials inoculated with either 0 or $10 \% \mathrm{D}$-virulent $P$. sorghi (i.e., $r$ values of 0.47 and 0.51 in 2003 and 0.37 and 0.65 in 2004). However, when rust severity was compared only among the $40 \mathrm{rp} 1 \mathrm{~d}$ hybrids, correlation coefficients among all trials ranged from 0.77 to 0.97 in 2003 and from 0.89 to 0.97 in 2004. Likewise, correlation coefficients among all trials for rust severity on the 40 Rp1D hybrids ranged from 0.55 to 0.95 in 2003 and from 0.83 to 0.95 in 2004.
Relationships between rust severity on Rp1D and rp1d versions of hybrids were explained by linear regressions in all trials (Figs. 3 and 4). Slope coefficients $\left(b_{1}\right)$ differed among trials and were related to the percentage of D-virulent $P$. sorghi in the initial inoculum (Fig. 5). Slopes were $0.21,0.29,0.51,0.64$, and 0.93 in 2003 and $0.25,0.50,0.67,0.76$, and 1.0 in 2004 for trials inoculated with $0,10,20,40$, and $100 \%$ D-virulent $P$. sorghi, respectively.

In both years, the unintended presence of D-virulent $P$. sorghi in the trials inoculated with $100 \%$ avirulent $P$. sorghi (i.e., $0 \%$ D-virulent) was evident from uredinia on hybrids with the RplD gene. Slope coefficients which were expected to be zero were 0.21 and 0.25 in these trials, indicating that about 21 and $25 \%$ of the infection in 2003 and 2004, respectively, was due to D-virulent $P$. sorghi. Similarly, a slope coefficient of 0.93 for the trial inoculated in 2003 with $100 \%$ D-virulent $P$. sorghi may have been indicative of infection of rpld hybrids in this trial by contaminant avirulent $P$. sorghi, although other factors, such as residual effects of ineffective host genes, offer alternative explanations for a slope lower than the expected value of 1.0.

The relationship between slope coefficients and the proportion of D-virulent inoculum was curvilinear (Fig. 5). Rust was about 65 to $75 \%$ as severe on Rp1D versions of hybrids as on the rpld versions of hybrids when $40 \%$ of the initial inocu- lum was D-virulent $P$. sorghi. When only $10 \%$ of the initial inoculum was Dvirulent, rust was only 30 to $50 \%$ as severe on Rp1D versions of hybrids as on rp1d versions of the same hybrids. These estimates, however, may have been biased by the natural occurrence or contaminant spread of D-virulent $P$. sorghi. Slope coefficients from trials inoculated with $100 \%$ avirulent $P$. sorghi were the best estimates of the influence of natural or contaminant unintended D-virulent inoculum in each year. Therefore, slope coefficients from trials inoculated with 10,20, and 40\% Dvirulent $P$. sorghi were adjusted for natural or unintended D-virulent inoculum by subtracting the slope $(0.21$ and 0.25 in 2003 and 2004, respectively) of the $100 \%$ avirulent trials (Fig. 6). When this adjustment was made, rust was estimated to be only 8 to $25 \%$ as severe on the Rp1D version of a hybrid as on the rp1d version of the same hybrid when D-virulent $P$. sorghi was $10 \%$ of the initial inoculum, 30 to $45 \%$ as severe when D-virulent $P$. sorghi was $20 \%$ of the initial inoculum, and 43 and $51 \%$ as severe when D-virulent $P$. sorghi was $40 \%$ of the initial inoculum (Fig. 6). Based on the adjusted slope coefficients, the $R p 1 D$ gene reduced rust severity 75 to $92 \%, 55$ to $70 \%$, and 49 to $57 \%$ when initial inocula consisted of 10, 20, and $40 \%$ D-virulent $P$. sorghi, respectively. When slope coefficients were not adjusted, estimates of control conveyed by the Rp $1 D$ gene were still 50 to $81 \%, 33$ to $49 \%$, and

Table 2. Correlations of common rust severity on 80 sweet corn hybrids in five trials each inoculated with different mixtures of Rp1D-virulent and Rp1D-avirulent Puccinia sorghi in 2003 and 2004

\begin{tabular}{lccccc}
\hline & \multicolumn{5}{c}{ D-virulent inoculum $(\boldsymbol{\%})^{\mathbf{a}}$} \\
\cline { 2 - 6 } D-virulent inoculum (\%) & $\mathbf{0}$ & $\mathbf{1 0}$ & $\mathbf{2 0}$ & $\mathbf{4 0}$ & $\mathbf{1 0 0}$ \\
\hline 0 & $\ldots$ & 0.96 & 0.92 & 0.85 & 0.47 \\
10 & $0.92^{\mathrm{c}}$ & $\ldots$ & 0.94 & 0.87 & 0.51 \\
20 & 0.77 & 0.94 & $\ldots$ & 0.95 & 0.67 \\
40 & 0.71 & 0.90 & 0.94 & $\ldots$ & 0.82 \\
100 & 0.37 & 0.65 & 0.78 & 0.84 & $\ldots$ \\
\hline
\end{tabular}

a Percentage of Rp1D-virulent inoculum in a given trial; correlation coefficients above the diagonal are for hybrids means from the five trials in 2003 and correlation coefficients below the diagonal are for hybrids means from the five trials in 2004.

Table 1. Summary statistics and mean separation values for comparing severity of common rust in five trials each in 2003 and 2004 in which 40 pairs of hybrids with and without the Rp1D gene were inoculated with mixtures of Rp1D-virulent and Rp1D-avirulent Puccinia sorghi

\begin{tabular}{|c|c|c|c|c|c|c|c|c|c|c|}
\hline \multirow[b]{3}{*}{ Year } & & & \multicolumn{8}{|c|}{ Rust severity (\%) } \\
\hline & \multicolumn{2}{|c|}{ Inocula $(\%)^{\mathrm{a}}$} & \multicolumn{4}{|c|}{ Hybrids with $r p 1 d$ genes $^{\mathrm{b}}$} & \multicolumn{4}{|c|}{ Hybrids with a $R p 1 D$ gene $^{b}$} \\
\hline & D-vir & avir & Mean & s.d. & Range & BLSD & Mean & s.d & Range & BLSD \\
\hline \multirow[t]{5}{*}{2003} & 0 & 100 & 25.1 & 10.6 & $2-48$ & 6.5 & 5.8 & 4.2 & $0.4-24$ & 3.5 \\
\hline & 10 & 90 & 26.8 & 10.1 & $2-47$ & 6.8 & 9.0 & 4.7 & $1-24$ & 3.5 \\
\hline & 20 & 80 & 32.8 & 11.4 & $4-72$ & 5.2 & 15.5 & 7.3 & $2-34$ & 3.7 \\
\hline & 40 & 60 & 31.1 & 10.3 & $7-65$ & 4.8 & 20.8 & 7.6 & 4-41 & 3.9 \\
\hline & 100 & 0 & 21.1 & 7.1 & $3-43$ & 2.3 & 20.5 & 6.8 & $2-39$ & 2.3 \\
\hline \multirow[t]{5}{*}{2004} & 0 & 100 & 35.6 & 8.6 & $14-62$ & 5.1 & 11.6 & 3.2 & $5-20$ & 2.6 \\
\hline & 10 & 90 & 37.7 & 11.4 & $8-73$ & 5.9 & 21.1 & 6.4 & $5-37$ & 3.2 \\
\hline & 20 & 80 & 36.6 & 12.4 & $6-72$ & 6.4 & 25.3 & 9.1 & $3-47$ & 6.4 \\
\hline & 40 & 60 & 39.4 & 11.6 & $11-78$ & 7.3 & 30.9 & 9.1 & $8-61$ & 4.7 \\
\hline & 100 & 0 & 41.8 & 10.8 & $16-72$ & 4.0 & 41.9 & 11.1 & $15-71$ & 4.0 \\
\hline
\end{tabular}

${ }^{a}$ Inocula consisting of different percentages of Rp1D-virulent (D-vir) and Rp1D-avirulent (avir) isolates of $P$. sorghi.

${ }^{\mathrm{b}}$ Abbreviations: s.d. $=$ standard deviation, Range $=$ range of hybrid means, and BLSD $=$ Bayesian least significant difference values $(k=100)$ for comparison of means of individual hybrids. 
24 to $36 \%$ when initial inocula consisted of 10, 20, and $40 \%$ D-virulent P. sorghi, respectively.

\section{DISCUSSION}

About $40 \%$ of commercially available sweet corn hybrids carry the $R p 1 D$ gene (15). Since 1999, Rp1D-virulent isolates of $P$. sorghi have occurred regularly in North America (21-23), but the frequency of D- virulence has not been documented. The frequency of virulence at which the $R p 1 D$ gene is completely ineffective is not known. When D-virulent $P$. sorghi was $100 \%$ of initial inoculum in our trials, resistance conveyed by the $R p 1-D$ gene was ineffective and common rust was equally severe on Rp1D and rpld versions of the same hybrids. Thus, like many $R$ genes, the $R p 1 D$ gene did not confer par-

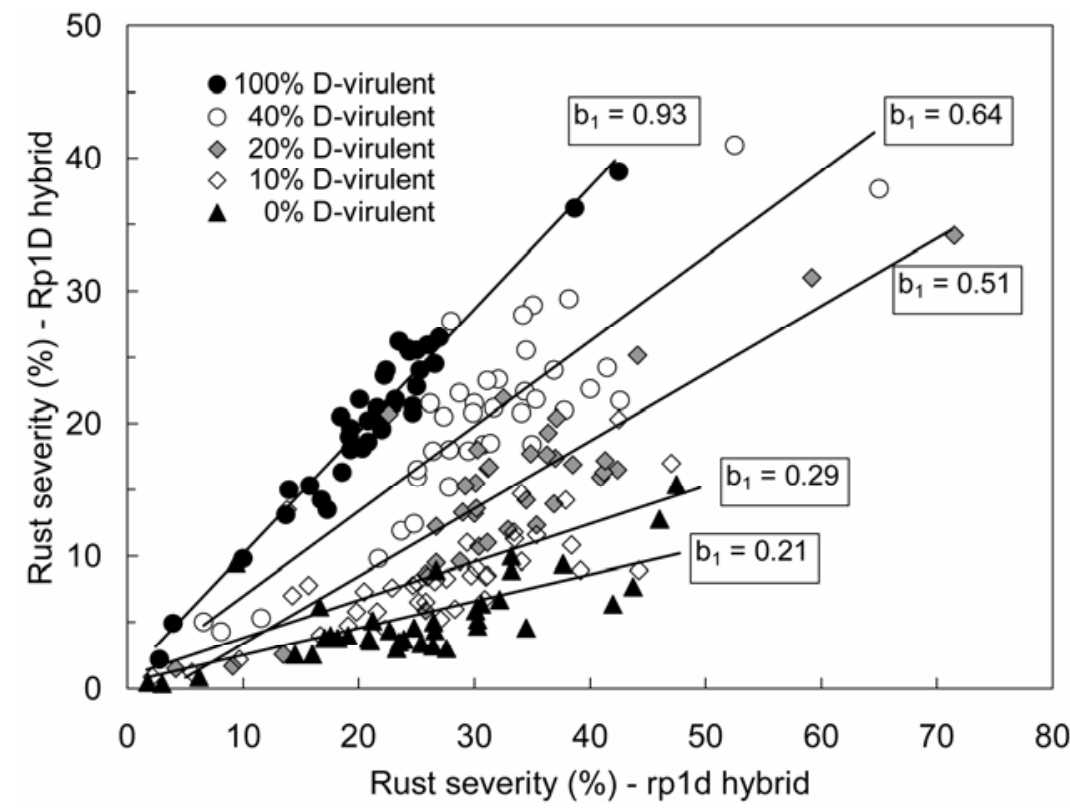

Fig. 3. Rust severity on 40 pairs of Rp1D and rp1d versions of sweet corn hybrids inoculated in five trials in 2003 with different mixtures of avirulent and Rp1D-virulent isolates of Puccinia sorghi in the approximate ratios of 100:0, 90:10, 80:20, 60:40, and 0:100. Slope coefficients $\left(b_{1}\right)$ estimate the severity of rust on the Rp1D version of a hybrid as a proportion of the severity on the rp1d version of a hybrid.

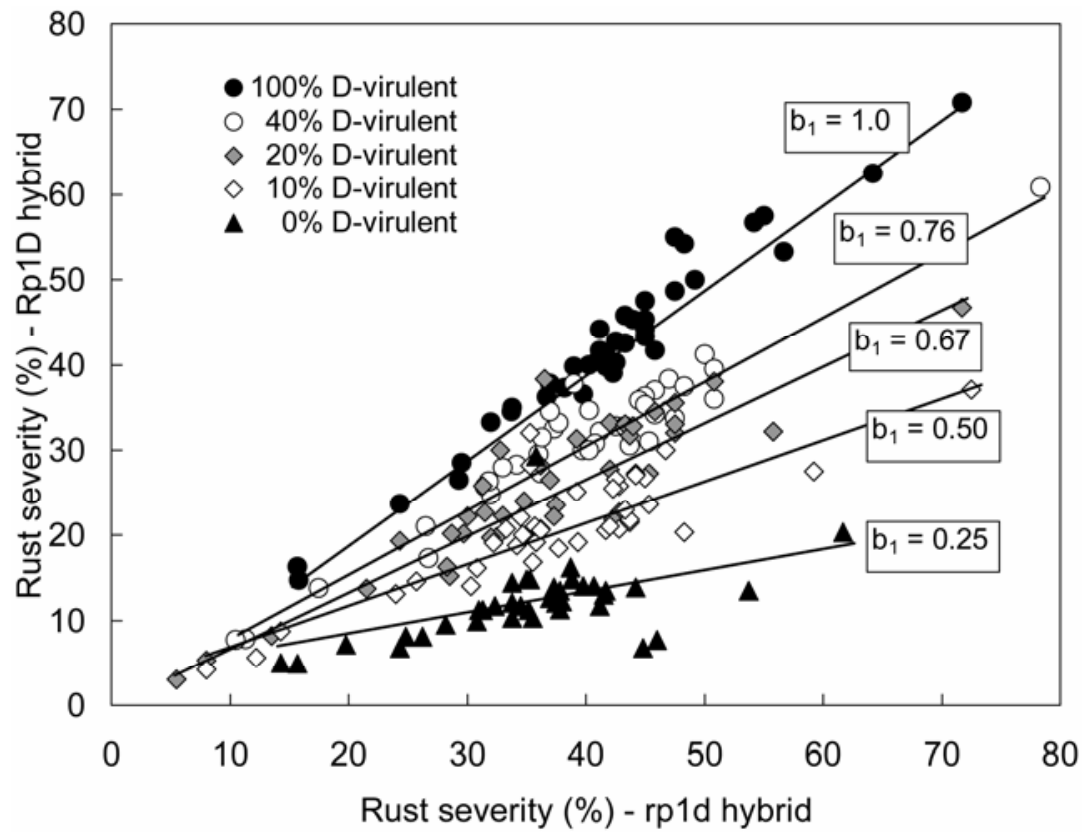

Fig. 4. Rust severity on 40 pairs of Rp1D and rp1d versions of sweet corn hybrids inoculated in five trials in 2004 with different mixtures of avirulent and Rp1D-virulent isolates of Puccinia sorghi in the approximate ratios of 100:0, 90:10, 80:20, 60:40, and 0:100. Slope coefficients $\left(b_{1}\right)$ estimate the severity of rust on the Rp1D version of a hybrid as a proportion of the severity on the rp1d version of a hybrid.

tial or residual resistance. When initial inocula consisted of $40 \%$ or less D-virulent P. sorghi, rust was significantly less severe on Rp1D versions than on rp1d versions of the same hybrids. In our trials, partial levels of control on hybrids carrying the $R p 1 D$ gene were proportional to the frequency of virulence in mixed populations of D-virulent and avirulent $P$. sorghi.

Although common rust is of relatively minor importance on field corn grown in North America, field corn plays an important role in determining the proportions of D-virulent and avirulent isolates in naturally occurring populations of $P$. sorghi in North America. A low amount of rust can be found in many fields of corn in the United States, but most crops of field corn grown in the U.S. corn belt avoid severe rust epidemics because of planting dates. Juvenile corn leaves are more susceptible to infection by $P$. sorghi than adult leaves $(1,7)$; however, field corn planted in the U.S. corn belt before mid-May usually has completed vegetative phase change and leaf whorls no longer consist of highly susceptible juvenile leaves when $P$. sorghi

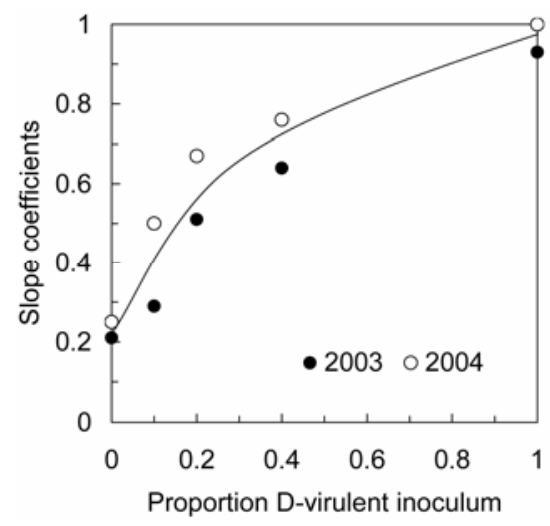

Fig. 5. Relationship between proportion of Rp1D-virulent Puccinia sorghi in initial inocula and slope coefficients from regressions of rust severity on Rp1D and rp1d versions of hybrids.

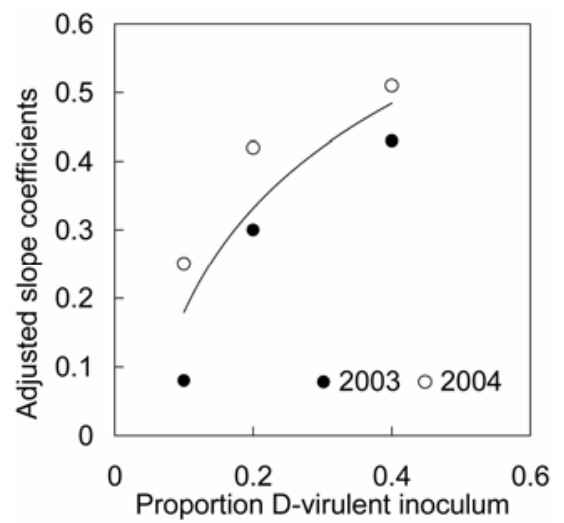

Fig. 6. Relationship between proportion of Rp1D-virulent Puccinia sorghi in initial inocula and slope coefficients from regressions of rust severity on Rp1D and rp1d versions of hybrids when slopes are adjusted by 0.21 and 0.25 in 2003 and 2004, respectively, for Rp1D-virulent P. sorghi in the $100 \%$ avirulent inoculum trial. 
inocula arrives from the southern areas of North America. Therefore, unlike sweet corn, the $R p 1 D$ gene and other $R p$ genes have not been deployed extensively in field corn hybrids grown in the United States. Because field corn acreage is over 100 times greater than sweet corn acreage, selection pressures that alter the frequency of D-virulent isolates of $P$. sorghi may be greater in sweet corn than in field corn, although inocula of both D-virulent and avirulent isolates may increase on field corn. On the other hand, the widespread occurrence of D-virulent P. sorghi in 1999 appears to have followed a limited use of the $R p 1 D$ gene in field corn hybrids in response to severe rust epidemics in 1993 when wet spring weather and flooding delayed planting in the Corn Belt until late May (12).

Although it is unlikely that extensive resources will become available to survey virulence of $P$. sorghi in North America, based on our results it appears that strategically located, paired plantings of Rp1D and rpld versions of sweet corn hybrids or hybrids with other $R p$ genes may be a simple way to monitor and roughly estimate the prevalence of virulence in $P$. sorghi. This type of monitoring program could be used to warn sweet corn producers growing mid- to late-season processing and fresh market sweet corn that is damaged most frequently and severely by rust.

Background levels of general resistance or susceptibility were evident from the range of severity observed among rp1d versions of hybrids and from high correlations among rust severity on Rp1D hybrids in trials inoculated with $10,20,40$, and $100 \%$ D-virulent $P$. sorghi. Based on an appropriate fit of linear regression models, control conveyed by the $R p 1 D$ gene in mixed populations of $P$. sorghi appeared to be similar among partially resistant and susceptible hybrids. In other words, in mixed populations of $P$. sorghi, the reduction in rust severity on the Rp1D version of partially resistant hybrids relative to the rp1d version of those hybrids was proportionally the same as the reduction in rust severity on the Rp1D version of susceptible hybrids relative to the rpld version of those hybrids.

Based on our results, it appears that mixed populations of D-virulent and avirulent $P$. sorghi could result in erroneous conclusions about hybrid reactions to rust (i.e., levels of general resistance or susceptibility) in some situations. If hybrids with and without the RplD gene are compared in a trial with low levels of D-virulent $P$. sorghi, hybrids with the RplD gene may appear to have greater levels of general resistance than rp1d hybrids even though the reduced amount of rust on Rp1D hybrids is primarily the result of a mixture of D-virulent and avirulent inocula. However, mixed populations of $P$. sorghi should not affect classification of hybrid reactions if rp1d and Rp1D hybrids are identified and their rust reactions are classified separately within those groups, or if D-virulent isolates compose a large portion of the inocula. Similarly, mixed populations of virulent and avirulent inocula could result in erroneous estimates of quantitative resistance (i.e., general resistance) associated with quantitative trait loci in chromosomal regions that contain $R p$ genes.

Additional experiments are necessary to determine whether or not the levels of control conveyed by the $R p 1 D$ gene against mixed populations of D-virulent and avirulent $P$. sorghi that we observed from comparisons of single-row plots of Rp1D and rp1d hybrids will occur in large contiguous fields planted to a single Rp1D hybrid.

\section{ACKNOWLEDGMENTS}

Seed of Rp1D and rp1d versions of hybrids were provided by Abbott and Cobb Inc., Crookham Company, General Mills Green Giant, Illinois Foundation Seeds Inc., Harris Moran Seed Company, and Rogers Seed. We thank M. Chandler and M. Meyers for critical review of drafts of this manuscript.

\section{LITERATURE CITED}

1. Abedon, B. G. 1997. Timing of vegetative phase change in maize: genetics and relationship with agronomic performance. Ph.D. dissertation, University of Wisconsin-Madison.

2. Bergquist, R. R. 1981. Transfer from Tripsacum dactyloides to corn of a major gene locus conditioning resistance to Puccinia sorghi. Phytopathology 71:518-520.

3. Bergquist, R. R., and Pryor, A. J. 1984. Virulence and isozyme differences for establishing racial identity in rusts of maize. Plant Dis. 68:281-283.

4. Dillard, H. R. and Seem, R. C. 1990. Use of an action threshold for common maize rust to reduce crop loss in sweet corn. Phytopathology 80:846-849.

5. Groth, J. V., Pataky, J. K., and Gingera, G. R. 1992. Virulence in eastern North American populations of Puccinia sorghi to Rp genes in corn. Plant Dis. 76:1140-1144.

6. Groth, J. V., Zeyen, R. J., Davis, D. W., and Christ, B. J.. 1983. Yield and quality losses caused by common rust (Puccinia sorghi Schw.) in sweet corn (Zea mays) hybrids. Crop Prot. 2:105-111.

7. Headrick, J. M., and Pataky, J. K. 1987. Expression of partial resistance to common rust in sweet corn hybrids at various host growth stages. Phytopathology 77:454-458.

8. Hooker, A. L. 1969 . Widely based resistance to rust in corn. Disease consequences of intensive culture of field crops. Iowa Agric. Home Econ. Exp. Stn. Spec. Rep. 64:28-34.

9. Hooker, A. L. 1985. Corn and sorghum rusts. Pages 208-236 in: The Cereal Rusts, Vol. 2. Academic Press, New York.

10. Hulbert, S. H. 1997. Structure and evolution of the rpl complex conferring rust resistance. Annu. Rev. Phytopathol. 35:293-310.

11. Hulbert, S. H., Lyons, P. C., and Bennetzen, J. L. 1991. Reactions of maize lines carrying $R p$ resistance genes to isolates of the common rus pathogen, Puccinia sorghi. Plant Dis. 75:11301133.

12. Munkvold, G. P., and Yang, X. B. 1995. Crop damage and epidemics associated with 1993 floods in Iowa. Plant Dis. 79:95-101.

13. Pataky, J. K. 1987. Quantitative relationships between sweet corn yield and common rust, Puccinia sorghi. Phytopathology 77:10661071.

14. Pataky, J. K. 1987. Reaction of sweet corn germ plasm to common rust and an evaluation of $R p$ resistance in Illinois. Plant Dis. 71:824 828 .

15. Pataky, J. K. 2004. Reactions of sweet corn hybrids to prevalent diseases: October 2004. Pages 119-142 in: Midwestern Vegetable Variety Trial Report for 2004, Purdue University, AES Bull. No. 2004-B17538.

16. Pataky, J., Campaña, A., and Michener, P 2002. Reactions of sweet corn hybrids to Rp1D-virulent rust. Pages 75-85 in: 2002 MWFPA Processing Crops Manual and Proceedings. Midwest Food Processors Associations, Madison, WI.

17. Pataky, J. K., Gonzalez, M., Brewbaker, J. L., and Kloppers, R. 2001. Reactions of Rpresistant sweet corn hybrids to populations of $P$. sorghi virulent on corn with the $R p 1-D$ gene. HortScience 36:324-327.

18. Pataky, J. K., Headrick, J. M., and Suparyono. 1988. Classification of sweet corn hybrid reactions to common rust, northern leaf blight, Stewart's wilt, and Goss's wilt and associated yield reductions. Phytopathology 78:172-178.

19. Pataky, J. K., Michener, P. M., Camapaña, A. and Babadoost, M. 2001. Sweet corn hybrid disease nursery-2001. Pages 121-135 in: Midwestern Vegetable Variety Trial Report for 2001, Purdue University, AES Bull. No. 808.

20. Pataky, J. K., Michener, P. M., Freeman, N. D., and Pate, M. C. 2000. Sweet corn hybrid disease nursery-2000. Pages 113-124 in: Midwestern Vegetable Variety Trial Report for 2000, Purdue University, AES Bull. No. 798.

21. Pataky, J. K., Natti, T. A., Snyder, E. B., and Kurowski, C. J. 2000. Puccinia sorghi in Sinaloa, Mexico virulent on corn with the Rp1-D gene. Plant Dis. 84:810.

22. Pataky, J. K., and Tracy, W. F. 1999. Widespread occurrence of common rust, caused by Puccinia sorghi, on Rp-resistant sweet corn in the midwestern United States. Plant Dis. 83:1177.

23. Pate, M. C., Pataky, J. K., Houghton, W. C., and Teyker, R. H. 2000. First report of Puccinia sorghi virulent on sweet corn with the Rp1-D gene in Florida and Texas. Plant Dis. 84:1154.

24. Shah, D. A., and Dillard, H. R. 2006. Yield loss in sweet corn caused by Puccinia sorghi: a meta-analysis. Plant Dis. 90:1413-1418. 